\title{
Histone deacetylase inhibitor AR-42 inhibits breast cancer cell growth and demonstrates a synergistic effect in combination with 5-FU
}

\author{
RUIHAO ZHOU ${ }^{1,2^{*}}$, JUAN WU $^{3 *}$, XIAOFENG TANG ${ }^{1}$, XIN WEI $^{1}$, CHENG JU $^{1}$, FEIFEI ZHANG ${ }^{1}$, \\ JUN SUN $^{1}$, DEYONG SHUAI ${ }^{1}$, ZHIPING ZHANG ${ }^{1}$, QIONG LIU ${ }^{4}$ and XIAO-BIN LV ${ }^{1}$ \\ ${ }^{1}$ Nanchang Key Laboratory of Cancer Pathogenesis and Translational Research, \\ The Third Affiliated Hospital, Nanchang University, Nanchang, Jiangxi 330008; ${ }^{2}$ First Clinical Department,
}

Medical School of Nanchang University, Nanchang, Jiangxi 330006; ${ }^{3}$ Guangzhou Key Laboratory of Translational Medicine on Malignant Tumor Treatment, Affiliated Tumor Hospital of Guangzhou Medical University, Guangzhou, Guangdong 510095;

${ }^{4}$ Department of Cardiovascular Medicine, Xiangya Hospital of Central South University, Changsha, Hunan 410008, P.R. China

Received October 4, 2017; Accepted April 6, 2018

DOI: $10.3892 / 01.2018 .8854$

\begin{abstract}
AR-42 is a member of a novelly discovered class of phenylbutyrate-derived histone deacetylase inhibitors, and has a number of antitumor effects in a variety of tumor types; however, the role of AR-42 and its possible mechanisms have not been reported in the treatment of breast cancer. The aim of the present study was to investigate the antitumor effects of AR-42 and its associated mechanisms in breast cancer. MTT assays and colony formation assays were conducted to measure the proliferation of MCF-7 cells, and flow cytometry was used to analyze cell apoptosis. The results revealed that AR-42 induced cell apoptosis and suppressed cell growth in a dose- and time-dependent manner. Mechanistically, AR-42 treatment increased the acetylation of the p53 protein and prolonged the half-life of the p53 protein; furthermore, AR-42 treatment upregulated p21 and PUMA expression. Notably, AR-42 had a synergistic effect on MCF-7 cells in combination with fluorouracil, which is one of the most commonly used chemotherapeutic agents. In conclusion, the results indicated that AR-42 inhibits breast cancer cell proliferation and induces
\end{abstract}

Correspondence to: Dr Xiao-Bin Lv, Nanchang Key Laboratory of Cancer Pathogenesis and Translational Research, The Third Affiliated Hospital, Nanchang University, 128 Xiangshan Northern Road, Nanchang, Jiangxi 330008, P.R. China

E-mail: nclvxiaobin@sina.cn

Dr Qiong Liu, Department of Cardiovascular Medicine, Xiangya Hospital of Central South University, 87 Xiangya Road, Changsha, Hunan 410008, P.R. China

E-mail: liuqiong9918@163.com

${ }^{*}$ Contributed equally

Key words: breast cancer cell, apoptosis, acetylation, synergistic effect, fluorouracil apoptosis, indicating that AR-42 is a potential therapeutic agent.

\section{Introduction}

Breast cancer is one of the most common and malignant tumor types among females globally, which accounts for $30 \%$ all new cancer diagnoses in females (1). Additionally, with a global annual increase of $\sim 200$ million patients, the mortality rate is increasing each year (2). On average there is a female diagnosed with breast cancer every three minutes globally (3). In China, the annual incidence of female breast cancer has experienced a sharp increase from 3 to $4 \%$ of the female population, which is notably higher than the average global growth rate for the diagnosis of breast cancer (4). Chemotherapy remains an important breast cancer treatment; however, clinical practice has confirmed that $30-50 \%$ of patients with breast cancer are either not sensitive to the treatment or the treatment does not produce effective results (5). Rather, they demonstrate heart and kidney side effects, which frequently cause extensive physical and mental harm to patients (6). Thus, it is a common goal of doctors and patients to discover novel drugs that improve the efficacy and reduce the toxicity of cancer treatments.

An increasing number of studies have focused on histone deacetylation, which is an important epigenetic modification involved in the development of numerous malignant tumor types, including melanoma, leukemia, prostate cancer, lung cancer and colon cancer (7-10). In the case of breast cancer, histone deacetylation is closely associated with the apoptosis, differentiation and down-regulation of tumor suppressor gene expression and cell sensitivity to drugs $(11,12)$. In the previous study, it was determined that the histone deacetylase (HDAC) regulator breast cancer metastasis-suppressor 1 like can regulate the activity of HDAC1/2 and inhibit the transcription of frizzled class receptor 10 and its downstream pathway, thus inhibiting the occurrence of epithelial-mesenchymal transition (EMT) in breast cancer (13). Inhibition of histone acetylase 
activity can induce breast cancer cell apoptosis, promote cancer cell differentiation, reduce drug resistance and inhibit tumor cell proliferation and the occurrence of EMT in breast cancer cells (14); therefore, targeting the specific inhibition of protein acetylation of enzymes may present an alternative treatment strategy for breast cancer.

Apoptosis serves an important role in cancer treatment and is a popular target of numerous treatment strategies due to its disorder being closely associated with tumor development $(15,16)$. In terms of cell growth arrest and apoptosis regulation, p53 serves an important role as a tumor suppressor $(17,18)$. By inactivating p53, cancer cells can avoid arrest despite carrying genetic damage (18). Previous studies demonstrated that the apoptosis-stimulating proteins phorbol-12-myristate-13-acetate-induced protein 1, p21 and PUMA may affect the progression of breast cancer through mediating the p53 pathway (19-21); therefore, studying the p53 pathway may identify novel therapeutic methods for breast cancer.

Recent advances in HDAC inhibitors have been encouraging. This is a class of compounds that target HDAC and focus on the malignant proliferation of cells through selective inhibition of growth and induction of apoptosis (14). Additionally, a recent study also determined that inhibitors may reverse multidrug resistance of tumors, and significantly reverse cisplatin resistance in ovarian cancer and colorectal cancer cells $(22,23)$. This demonstrates the potential research and developmental value of multidrug resistance drug reversal agents.

AR-42 is a novelly discovered class of phenylbutyrate protein deacetylase inhibitors that display localized enrichment in tumor tissues (24). AR-42 was initially determined to be effective in various blood tumor types, including leukemia, lymphoma and other blood tumor types, and it serves a role in the inhibition of tumor growth $(25,26)$. Previous studies demonstrated AR-42 to have antitumor effects in solid tumor types, including hepatocellular carcinoma, ovarian cancer and pancreatic cancer (27-29). In addition, AR-42 was determined to have a synergistic effect with cisplatin (30), indicating a potential antitumor effect of AR-42. The role of AR-42 in breast cancer remains unclear; therefore, the aim of the present study was to investigate the antitumor effects of AR-42 and its associated mechanisms in breast cancer.

\section{Materials and methods}

Cell culture. The human breast cancer MCF-7 cell line was provided by the American Type Culture Collection (Manassas, VA, USA). MCF-7 cells were cultured with Dulbecco's modified Eagle's medium (Gibco; Thermo Fisher Scientific, Inc. Waltham, MA, USA) containing $10 \%$ fetal bovine serum (Thermo Fisher Scientific, Inc.) and incubated in a $5 \% \mathrm{CO}_{2}$ atmosphere at $37^{\circ} \mathrm{C}$.

Antibodies and chemicals. AR-42 (Arno Therapeutics, Flemington, NJ, USA) and cycloheximide (CHX) were prepared in dimethyl sulfoxide (Sigma-Aldrich; Merck KGaA, Darmstadt, Germany). The CHX chase assay identified the p53 degradation half-life. Anti- $\beta$-actin (cat. no. sc-47778; 1:1,000), rabbit anti-p53 (cat. no. sc-6243; 1:1,000) and anti-Ac-lysine (cat. no. sc-81623; 1:1,000) antibodies were purchased from Santa Cruz Biotechnology (New York, USA). Horseradish peroxidase (HRP)-conjugated anti-mouse (cat. no. 7076; 1:2,000) and anti-rabbit (cat. no. 7074; 1:2,000) IgG were purchased from Cell Signaling Technology, Inc. (Danvers, MA, USA).

Cell viability assay. Cells were plated in 96-well plates at density of 5,000 cells/well and were treated with AR-42 (0.025, 0.05, 0.1, 0.2, 0.4 and $0.8 \mu \mathrm{mol} / 1$; cat. no. S2244; Selleck Chemicals, Houston, TX, USA) and/or 5-FU $(0,0.25,0.5,0.1$ and $0.2 \mu \mathrm{mol} / 1$; cat. no. F6627; Sigma Aldrich; Merck KGaA). After $72 \mathrm{~h}$ of drug exposure at $37^{\circ} \mathrm{C}$, cells were treated with MTT solution $(5 \mathrm{mg} / \mathrm{ml})$, to dissolve the purple formazan, for an additional $4 \mathrm{~h}$ at $37^{\circ} \mathrm{C}$, and the optical density (OD)490 value was detected using enzyme labeling apparatus (ELx800 Strip Reader; BioTek Instruments, Inc., Winooski, VT, USA), reflecting the number of viable cells. Cytotoxicity $(\%)=(1-O D 490$ of experimental well)/OD490 of control well.

Colony formation assays. The cells were digested with $0.25 \%$ trypsin solution at $37^{\circ} \mathrm{C}$ for 2 mins and prepared for single cell suspension. They were seeded into 6-well plates (Wuxi Nest Biotechnology, Co. Ltd., Jiangsu, China) with 1,000 cells/per well cultured with Dulbecco's modified Eagle's medium supplemented with $10 \%$ fetal bovine serum (Thermo Fisher Scientific, Inc.), then gently shook to evenly disperse in the cells normal culture conditions. Following incubation at $37^{\circ} \mathrm{C}$ for two weeks, the cells were carefully washed twice with PBS, fixed for 15 min with $100 \%$ methanol and stained for 15 min with $0.1 \%$ crystal violet dye at room temperature. Water was then used to slowly wash away the dyeing liquid, and the cells were left to dry naturally in the air. The $0 \mu \mathrm{M}$ AR-42 was the negative control group. Each experiment was repeated at least three times.

Apoptosis assay. MCF-7 cells were treated with 0, 0.025, 0.05, 0.1 or $0.2 \mu \mathrm{M} \mathrm{AR}-42$ at $37^{\circ} \mathrm{C}$ for $48 \mathrm{~h}$ in culture conditions, and then harvested and washed with PBS twice. The cells were collected and stained with an Annexin V/PI double flow cytometry kit (Nanjing KeyGen Biotech, Co., Ltd., Nanjing, China), according to the manufacturer's protocol, to detect the cell apoptosis rate. The $0 \mu \mathrm{M}$ AR-42 were the negative control. Each experiment was repeated at least three times.

Analysis of in vitro drug interaction. Analysis of the drug's synergistic inhibitory effect was determined using the coefficient of drug interaction (CDI) metric. CDI was calculated as follows: $\mathrm{CDI}=\mathrm{AB} /(\mathrm{A} * \mathrm{~B})$. $\mathrm{A}$ or $\mathrm{B}$ is the ratio of the single drug group to the control group in OD490 and AB represents the ratio of the two-drug combination group to the control group in OD490. CDI $>1$ signifies antagonism, $\mathrm{CDI}=1$ indicates additivity, and $\mathrm{CDI}<1$ indicates synergism. $\mathrm{A} \mathrm{CDI}<0.7$ was considered to indicate a statistically significant synergistic effect.

Western blotting and immunoprecipitation. Procedures were conducted as previously described (31). Following extraction of total cellular protein, the protein concentration was determined by the BCA method. The sample was mixed 
with loading buffer (cat. no. P0015; Beyotime Institute of Biotechnology, Shanghai, China) and placed in a boiling water bath for $10 \mathrm{~min}$, and following 10\% SDS-PAGE electrophoresis (30 $\mu \mathrm{g} /$ lane) was transferred to a polyvinylidene fluoride membrane. The membranes were incubated in 5\% skim milk at room temperature for $2 \mathrm{~h}$. The membranes were incubated with antibodies against human p53 or $\beta$-actin overnight at $4^{\circ} \mathrm{C}$ and incubated at room temperature for $2 \mathrm{~h}$ with anti-mouse and anti-rabbit IgG HRP-conjugated antibodies. The chemiluminescence system was exposed to enhanced chemiluminescent (Advansta, Inc., Menlo Park, CA, USA; R-03025-D25), and the experiment was repeated three times. ImageJ $1.50 \mathrm{f}$ software (National Institutes of Health, Bethesda, MD, USA) was used for densitometric analysis of the experimental data.

To investigate the interaction between AR-42 and Ack-p53 at the endogenous level, the clarified supernatants were first incubated with anti-p53 or anti-Ac-lysine for $2 \mathrm{~h}$ at $4^{\circ} \mathrm{C}$. Protein $\mathrm{A} / \mathrm{G}$-agarose was then added and incubated for $2 \mathrm{~h}$ to overnight. Precipitates were washed four times with RIPA buffer (Beyotime Institute of Biotechnology) and analyzed by western blotting as aforementioned. ImageJ 1.50 f software was used for densitometric analysis of the experimental data.

$R N A$ extraction and reverse transcription-quantitative polymerase chain reaction $(R T-q P C R)$. Total RNA was extracted using TRIzol ${ }^{\circledR}$ (Invitrogen; Thermo Fisher Scientific, Inc.), according to the manufacturer's protocols. cDNA was synthesized with the MLv transcriptase kit (Invitrogen; Thermo Fisher Scientific, Inc.). The quantitative analysis of p21 and puma expression was assayed using a SYBR ${ }^{\circledR}$ green kit (Takara Bio, Inc., Otsu, Japan) with gene-specific primers. Primer sequences for $\mathrm{p} 21$, puma, and $\beta$-actin were as follows: p21, forward,. 5'-GCTCGGCTCTTCACCAAG-3', and reverse, 5'-GTCACTGTCTTGTACCCTTGTG-3'; puma, forward, 5'-CGACCTCAACGCACAGTACGA-3', and reverse, 5'-AGGCACCTAATTGGGCTCCAT-3'; $\beta$-Actin, forward, 5'-GGTGGCTTTTAGGATGGCAAG-3', and reverse, 5'-ACT GGAACGGTGAAGGTGACAG-3'. $\beta$-Actin was used as a normalization control. The standard PCR conditions were: $95^{\circ} \mathrm{C}$ for $15 \mathrm{mins}$, followed by 40 cycles of $95^{\circ} \mathrm{C}$ for $5 \mathrm{sec}$, $60^{\circ} \mathrm{C}$ for $30 \mathrm{sec}$, and $72^{\circ} \mathrm{C}$ for $40 \mathrm{sec}$. The fold changes were calculated through relative quantification with $2^{-\Delta \Delta \mathrm{Cq}}$ (32). All of the reactions were performed in a $20 \mu \mathrm{l}$ reaction volume in triplicate. These experiments were repeated at least three times independently.

Statistical analysis. SPSS 16 software (SPSS, Inc., Chicago, IL, USA) was used for statistical analysis of the experimental data. Values are expressed in triplicate and presented as the mean \pm standard deviation. Comparisons were conducted using One-way analysis of variance followed by Tukey's post hoc test for multiple comparisons. $\mathrm{P}<0.05$ was considered to indicate a statistically significant difference.

\section{Results}

AR-42 inhibits the growth of the MCF-7 cell line in a dose- and time-dependent manner. Previous studies have demonstrated the antitumor effects of AR-42 in blood tumor and solid tumor types (25-29). To investigate the antitumor effects of AR-42 in breast cancer, the MCF-7 cell line was treated with AR-42 at concentrations of $0-0.8 \mu \mathrm{M}$ for different periods of time. The MTT assay was used to evaluate cell viability. As depicted in Fig. 1A and B, AR-42 inhibits MCF-7 cell growth in a dose- and time- dependent manner. Furthermore, the colony formation assays (Fig. 1C) indicated that AR-42 inhibited colony formation in a dose-dependent manner.

AR-42 inhibits the growth of MCF-7 cells by promoting apoptosis. Inhibition of cell growth may be the result of apoptosis, induction of necrosis or cell cycle arrest (15). Apoptosis is a programmed cell death process regulated by multiple genes, and its disorder is closely associated with the development of tumors (16). To detect whether AR-42 affects the apoptotic rate of MCF-7 cells, flow cytometry was performed on the cells. As depicted in Fig. 2, following treatment with 0-0.2 $\mu \mathrm{M}$ AR-42 for $48 \mathrm{~h}$, the survival ratios of MCF-7 cells were decreased from $86.05 \%$ to $81.77,74.18,63.51$ and $60.86 \%$ as the AR-42 concentration increased from 0.0 to $0.2 \mu \mathrm{m}$ (Fig. 2. $\mathrm{P}<0.01$ vs. control group). These results indicated that AR-42 inhibits the growth of MCF-7 cells by promoting cell apoptosis.

AR-42 induces MCF-7 cell apoptosis by increasing the acetylation level of p53. Acetylation has been reported to increase the activity and stability of p53 $(33,34)$. To understand the mechanisms underlying AR-42 mediated apoptosis in MCF-7 cells, whether AR-42 affects p53 acetylation level was investigated. As depicted in Fig. 3A and B, the expression of acetylated p53 was elevated following treatment with AR-42. Furthermore, the $\mathrm{CHX}$ chase assay results indicated that AR-42 prolonged the half-life of the p53 protein, indicating that AR-42 increased the stability of the p53 protein. p21 and PUMA are important downstream transcriptional targets of p53 (20); their mRNA levels following AR-42 treatment in MCF-7 cells was examined. As depicted in Fig. 3C, AR-42 treatment induced p21 and PUMA expression in MCF-7 cells in a dose-dependent manner.

AR-42 combined with 5-FU has a synergistic inhibitory effect on MCF-7 cells. Chemotherapy remains an important breast cancer treatment. As a conventional chemotherapy drug, 5-FU can effectively improve the survival rate of clinical patients (35). Previous study demonstrated that 5-FU has serious side effects, such as cytotoxicity, leading to a narrow therapeutic effect (35); therefore, it's necessary to investigate possible synergistic effects of combining 5-FU and AR-42 in MCF-7 cells. As depicted in Fig. 4A, the results revealed that AR-42 increased the cytotoxicity of 5-FU towards MCF-7 cells. The synergistic effect is indicated as a CDI value. As presented in Fig. 4B, $0.25 \mu \mathrm{M} 5$-FU combined with $0.2 \mu \mathrm{M}$ AR-42 had the most significant synergistic effect $(\mathrm{CDI}<0.7)$.

\section{Discussion}

Breast cancer is known to be one of the most widespread and prevalent tumor types globally (1). Breast cancer cases in China account for $12 \%$ of the global total novel diagnosed cases of breast cancer each year (4); therefore, it is necessary to investigate novel strategies for breast cancer treatment. 

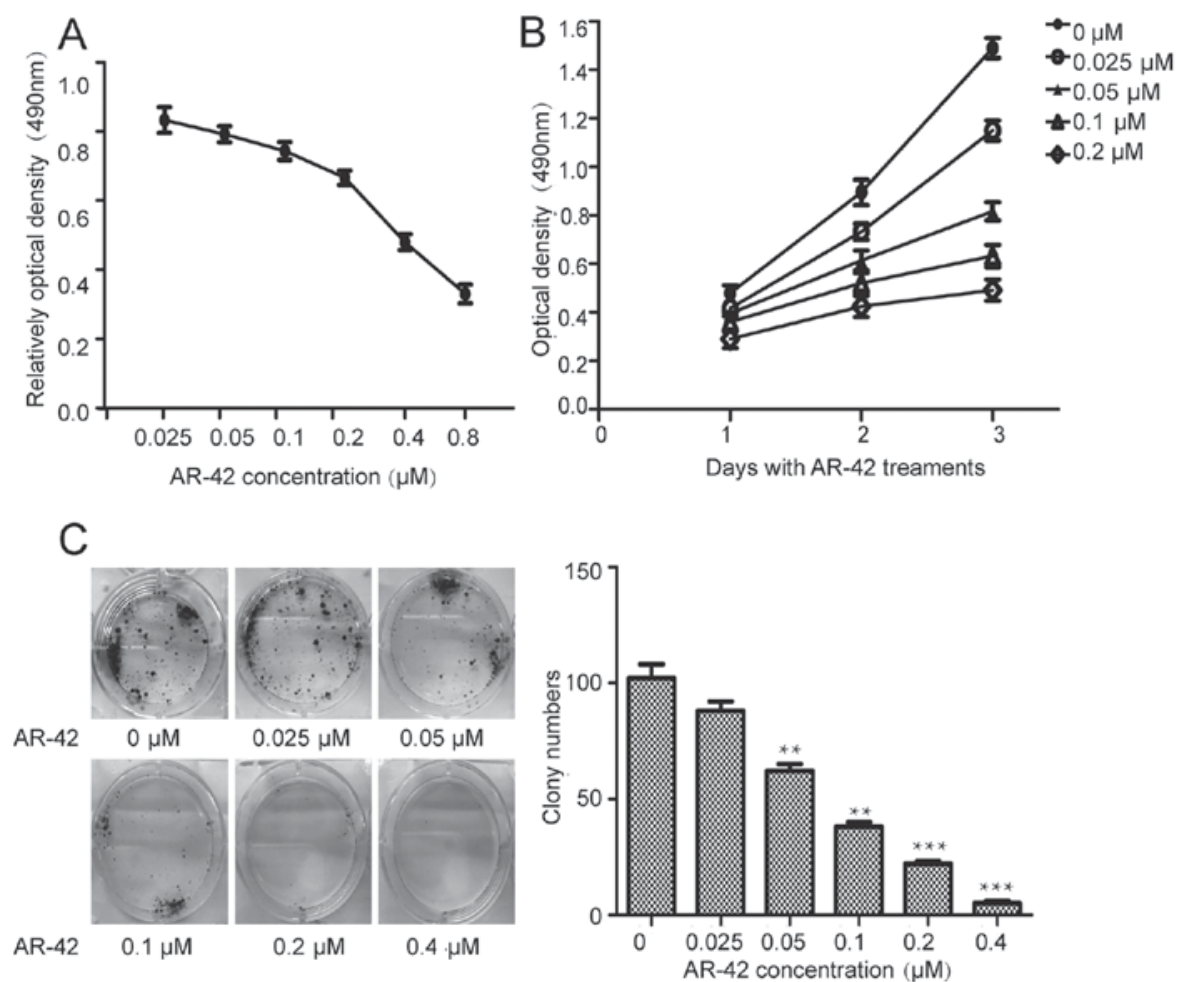

Figure 1. AR-42 inhibited the growth of MCF-7 cells in a dose- and time-dependent manner. (A) MCF-7 cells underwent treatment with various concentrations of AR-42 (0.0-0.8 $\mu \mathrm{M})$ for three days. The average of three independent experiments is displayed. (B) A total of 0.0-0.2 $\mu$ M AR- 42 was administered to MCF-7 cells for three days, and the absorbance was quantified daily. The average of three independent experiments is displayed. (C) MCF-7 cells were plated into 6-well plates (1,000 cells/well). The medium with 0.0-0.4 $\mu \mathrm{M}$ AR-42 was changed every four days, and for colony assays, the cells were stained with crystal violet two weeks following each treatment. ${ }^{* *} \mathrm{P}<0.01 ;{ }^{* * *} \mathrm{P}<0.001$ vs. control group. OD, optical density.
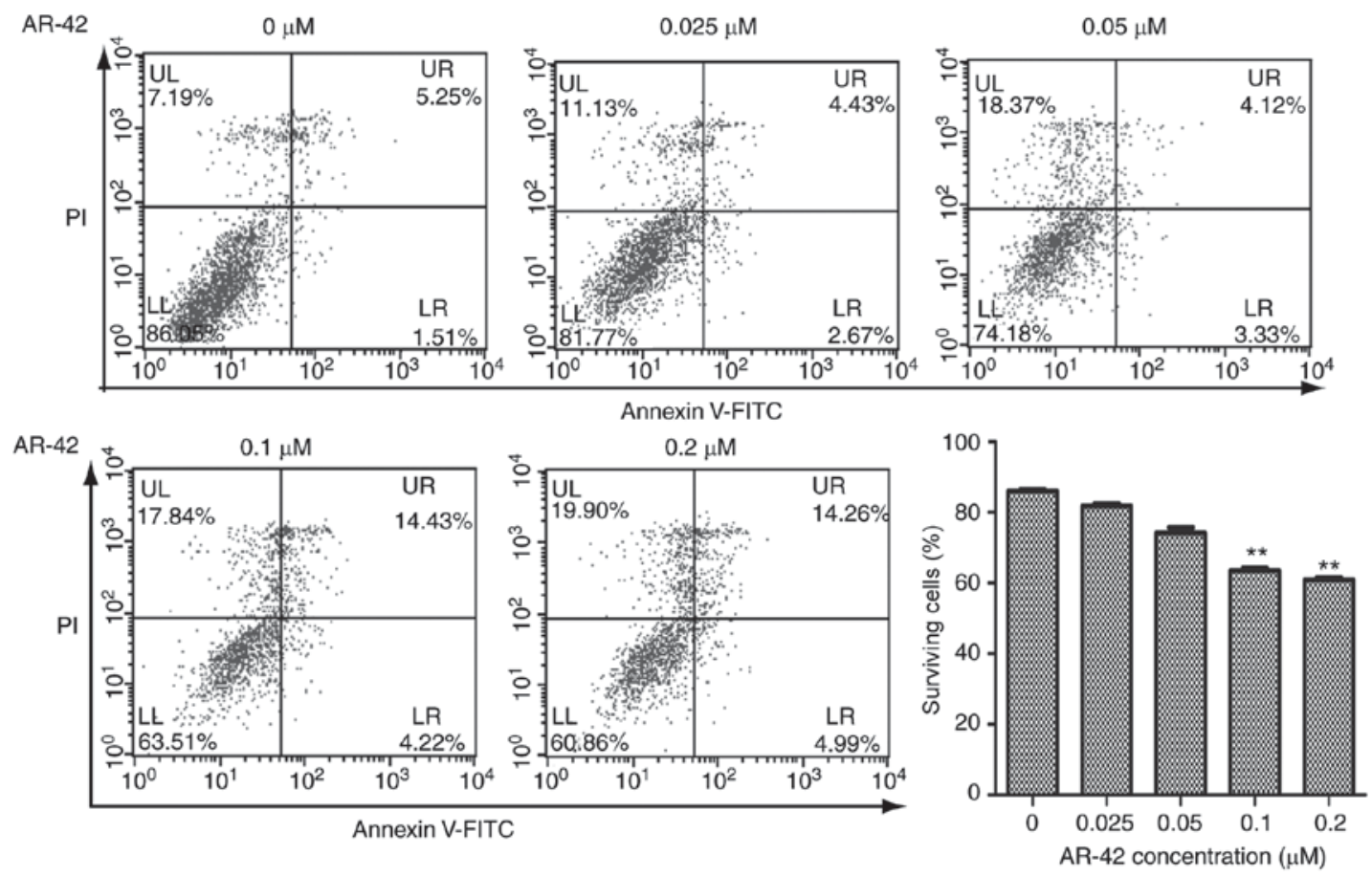

Figure 2. AR-42 inhibited the growth of MCF-7 cells by promoting apoptosis. Cell apoptosis levels were evaluated by flow cytometry. Apoptosis analysis was conducted on cells treated with $(0.0-0.2 \mu \mathrm{M})$ AR- 42 for $48 \mathrm{~h}$. $\mathrm{n}=3$. Surviving cells were determined to be the total Annexin V/FITC-negative cells. Data are presented as the mean \pm standard deviation, $n=3$. ${ }^{* *} \mathrm{P}<0.01$ vs. control group. PI, propidium iodide; FITC, fluorescein isothiocyanate.

HDAC inhibitors represent a novel anticancer therapeutic strategy (36). A significant number of HDAC inhibitors have been developed in the past decade (3). Previous studies have demonstrated that AR-42, a member of a novelly discovered 


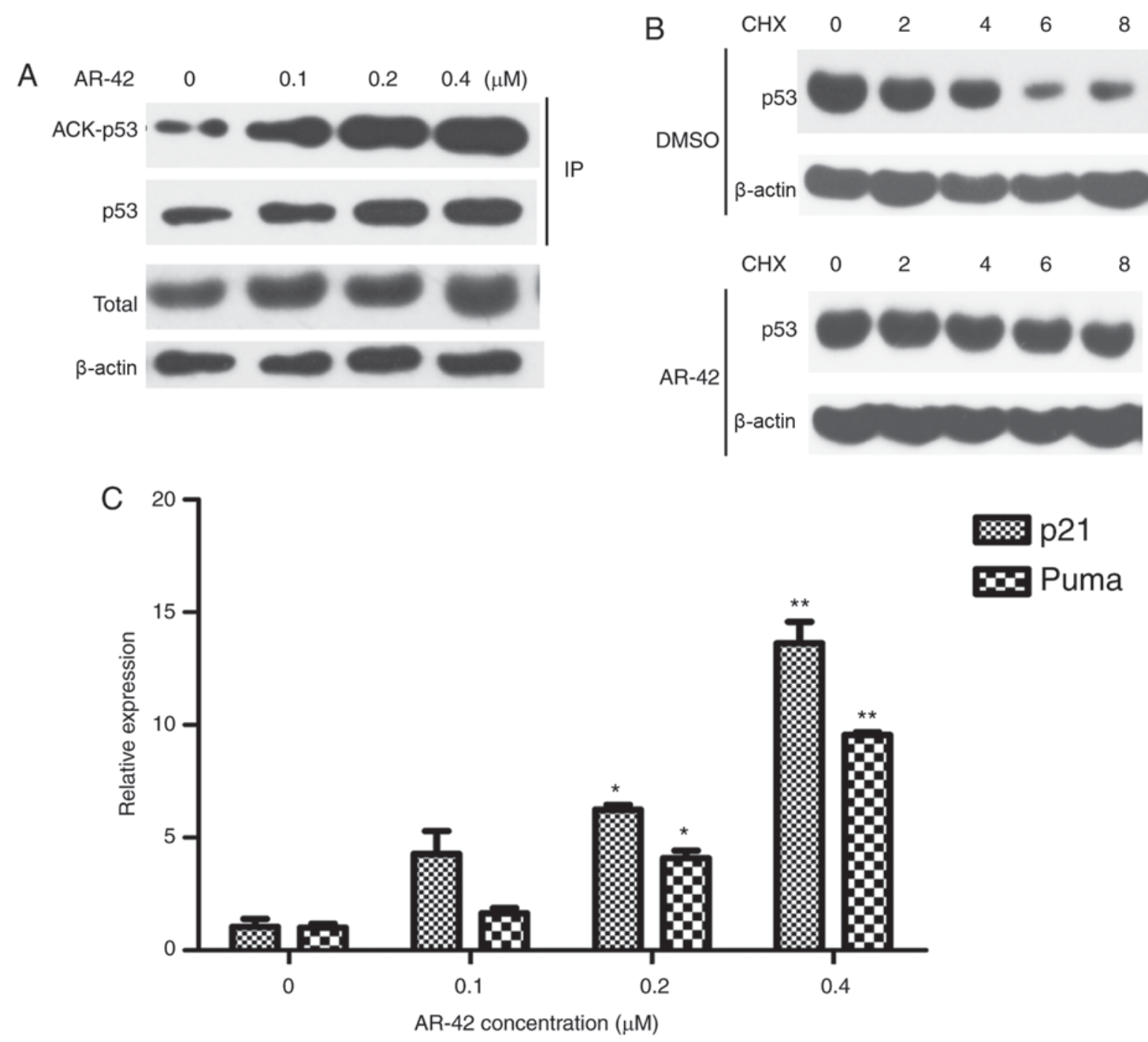

Figure 3. AR-42 induced MCF-7 cells apoptosis by increasing p53, its acetylation and expression of p21 and PUMA. (A) AR-42 treatment upregulated p53 and its acetylation. Western blotting and immunoprecipitation procedures were conducted on MCF-7 cells treated with 0.0-0.4 $\mu \mathrm{M}$ AR-42 for 48 h. (B) AR-42 prolonged the half-life of the p53 protein, as measured by the CHX chase assay, which identified the p53 degradation half-life. (C) p21 and PUMA were expressed in a dose-dependent manner in MCF-7 cells in response to AR-42 treatment. Using reverse transcription-quantitative polymerase chain reaction, the gene expression of p21 and PUMA was determined in cells treated with 0-0.4 $\mu \mathrm{M}$ AR- 42 for $48 \mathrm{~h}$. Data are the mean of at least three independent experiments. ${ }^{*} \mathrm{P}<0.05 ;{ }^{* *} \mathrm{P}<0.01$ vs. control group. CHX, cycloheximide; DMSO, dimethyl sulfoxide; IP, immunoprecipitation.

class of phenylbutyrate-derived HDAC inhibitors, has been demonstrated to have antitumor effects in blood tumor and solid tumor types (24-26). Apoptosis disorders are closely associated with the development of tumors (15); therefore, the induction of tumor cell apoptosis may be an efficient strategy to prevent tumor progression. In the present study, it was demonstrated that AR-42 inhibited the proliferation of MCF-7 breast cancer cells by indirectly regulating acetylation of the p53 protein, which also indicated a synergistic effect when combined with 5-FU. The results indicated that the proliferation of breast cancer cells may be suppressed by AR-42 treatment, which may prove to be an alternative therapeutic approach for the future treatment of breast cancer.

Apoptosis is a programmed cell death process regulated by multiple genes, and its disorder is closely associated with the development of tumors (15). In terms of cell growth arrest and apoptosis regulation, p53 serves an important role as a tumor suppressor by inducing extrinsic and intrinsic apoptotic pathways to ensure efficient death responses $(17,37)$. Acetylation is essential for p53 activity, and its function is important in transcriptional activation and senescence $(33,34)$. Acetylation of p53 affects cell activity and function, such as Lys-373 and Lys-382 acetylation, which inhibits p53 degradation, thereby mediating apoptosis and enhancing cell drug sensitivity (34). It has been demonstrated that treatment of colon cancer cells with SIRTI siRNA or the HDACI MS275 can increase p53 acetylation levels and enhance paclitaxel-induced apoptosis (38). The SIRT1 small molecule inhibitor Tenovin-1 can inhibit increased p53 expression and activity levels and inhibit melanoma cell proliferation $(38,39)$. As depicted in Fig. 3, the results indicated that AR-42 treatment increased the level of p53 protein and its acetylation formation. In addition, AR-42 treatment significantly prolonged the half-life of the p53 protein. It is notable that p53 acetylation itself is effective in stabilizing and increasing the level of total p53 (40).

As a result, the accumulation of the p53 protein and its acetylation may be the consequence of AR-42-mediated apoptosis in MCF-7 cells. The tumor suppressor protein p53 affects 


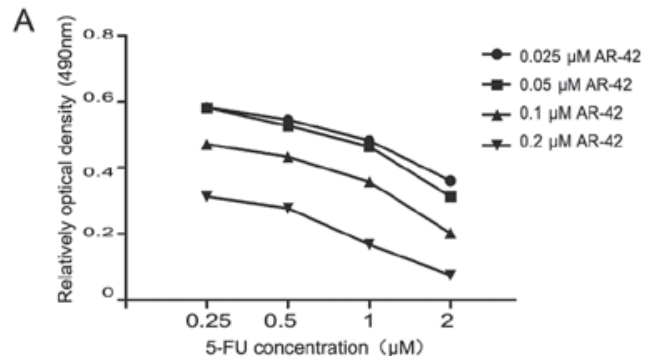

B

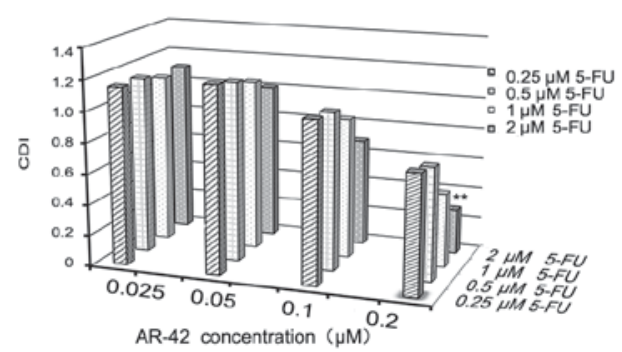

Figure 4. Synergistic inhibitory effect of AR-42 combined with 5-FU in MCF-7 cells. (A) MCF-7 cells were either treated exclusively with $0.25-2.0 \mu \mathrm{M} 5$-FU or combined with $0.025,0.05,0.1$ or $0.2 \mu \mathrm{M}$ AR-42. Cell viability was examined using an MTT assay three days following treatment. (B) Analysis of the synergistic inhibitory effect of different concentrations of AR-42 and 5-FU was revealed using CDI. $\mathrm{n}=3 .{ }^{* *} \mathrm{P}<0.01$ vs. $0.25 \mu \mathrm{M}$ 5-FU and $0.025 \mu \mathrm{M}$ AR-42. CDI, coefficient of drug interaction; OD, optical density; 5-FU, fluorouracil.

a vast number of downstream targets and performs a braking function by blocking injured cells from entering the cell cycle and promoting apoptosis (18). Among these downstream targets are p21 and PUMA, which are major mediators of the function of p53 (41). Previous studies performed on other cancer cell lines have demonstrated that HDAC inhibition results in the upregulation of p21 and PUMA expression through increasing the acetylation of p53 $(20,21,42)$. In the present study, AR-42 increased p21 and PUMA expression, confirming p53 activation; therefore, AR-42 treatment may successfully induce molecular mediators of cell cycle arrest and apoptosis.

Currently, chemotherapy remains an important breast cancer treatment. As a conventional chemotherapy drug, 5-FU can effectively improve the survival rate of clinical patients. However, it has serious limitations, such as cytotoxicity, which leads to its narrow therapeutic effect $(35,43)$. Thus, combining 5 -FU with other pharmaceutical agents will provide more effective ways to sensitize cancer cells to chemotherapy, while reducing toxicity to normal cells (35). Combination therapy may achieve fewer side effects and greater therapeutic efficacy. The results indicated that AR-42 increased the cytotoxicity of 5-FU and indicated a significant synergistic effect when combined with 5-FU, which indicates that the combined treatment of AR-42 and 5-FU may be an effective strategy for treating breast cancer.

5-FU serves an important role in early breast cancer treatment following adjuvant therapy, breast cancer recurrence and metastasis following palliative care $(43,44)$. It is an anti-metabolic chemotherapeutic agent, acting mainly through the irreversible inhibition of thymidylate synthase (TS), which results in a lack of thymine and the synthesis of non-functional DNA (35). A previous study demonstrated that p53 is important for drug sensitivity to TS inhibitors, such as 5-FU (45). It has been previously reported that acetylation of p53 is essential for preventing degradation and opening a conformation that allows binding to DNA (46). 5-FU mediated DNA damage activates numerous signaling pathways, such as p53-mediated apoptosis. The results indicated that AR-42 treatment caused MCF-7 cell apoptosis. It was demonstrated that AR-42 and 5-FU have the ability to activate p53-mediated apoptosis, which may clarify how AR-42 synergistically combines with 5-FU to restrain the growth of MCF-7 cells; however, the specific mechanisms underlying the synergistic effect of AR-42 and 5-FU require further study.

In conclusion, the present study investigated the anti-tumorigenic role of AR-42 in breast cancer cells. The results demonstrated that AR-42 inhibits the proliferation of MCF-7 breast cancer cells via the induction of cell apoptosis. Notably, combination assays demonstrated that joint AR-42 and 5-FU treatment have a significant synergistic effect on MCF-7 breast cancer cells.

\section{Acknowledgements}

Not applicable.

\section{Funding}

This study was supported by the National Natural Science Foundation of China (grant nos. 81201550, 81560452 and 81672866), the Zhujiang Star 2015 of Science and Technology Program of Guangzhou, China (grant no. 201506010037), the Natural Science Foundation of Jiangxi Province (grant nos. 20161BAB205192 and 20171ACB21073), the Excellent Youth Foundation of Jiangxi Scientific Committee (grant no. 20162BCB23001), the Science and Research Fund of Jiangxi Health and Family Planning Commission (grant no. 20164002) and The Foundation of Nanchang Science and Technology Bureau (grant no. 2016 ZSCX 009).

\section{Availability of data and materials}

The datasets used and/or analyzed during the current study are available from the corresponding author on reasonable request.

\section{Authors' contributions}

RZ and JW designed the research, analyzed data, and wrote the manuscript. XT, XW, CJ, FZ performed experiments and prepared the figures. JS, DS and $\mathrm{ZZ}$ were involved in drafting the manuscript, revising it critically for important intellectual content, designed the study and acquired the data. XBL and QL participated in the design of the study and helped finalize the manuscript. All authors read and approved the final manuscript.

\section{Ethics approval and consent to participate}

Not applicable.

\section{Consent for publication}

Not applicable. 


\section{Competing interests}

The authors declare that they have no competing interests.

\section{References}

1. Torre LA, Bray F, Siegel RL, Ferlay J, Lortet-Tieulent J and Jemal A: Global cancer statistics, 2012. CA Cancer J Clin 65: 87-108, 2015.

2. Siegel RL, Miller KD and Jemal A: Cancer statistics, 2018. CA Cancer J Clin 68: 7-30, 2018.

3. Turtoi A, Peixoto P, Castronovo V and Bellahcene A: Histone deacetylases and cancer-associated angiogenesis: Current understanding of the biology and clinical perspectives. Crit Rev Oncog 20: 119-137, 2015.

4. Fan L, Strasser-Weippl K, Li JJ, St Louis J, Finkelstein DM, Yu KD, Chen WQ, Shao ZM and Goss PE: Breast cancer in China. Lancet Oncol 15: e279-e289, 2014.

5. Meattini I, Curigliano G, Terziani F, Becherini C, Airoldi M, Allegrini G, Amoroso D, Barni S, Bengala C, Guarneri V, et al: SAFE trial: An ongoing randomized clinical study to assess the role of cardiotoxicity prevention in breast cancer patients treated with anthracyclines with or without trastuzumab. Med Oncol 34 75, 2017.

6. Zhu L, Wu K, Ma S and Zhang S: HDAC inhibitors: A new radiosensitizer for non-small-cell lung cancer. Tumori 101: 257-262, 2015.

7. Marti RM, Sorolla A and Yeramian A: New therapeutic targets in melanoma. Actas Dermosifiliogr 103: 579-590, 2012 (In English; In Spanish).

8. Eigl BJ, North S, Winquist E, Finch D, Wood L, Sridhar SS, Powers J, Good J, Sharma M, Squire JA, et al: A phase II study of the HDAC inhibitor SB939 in patients with castration resistant prostate cancer: NCIC clinical trials group study IND195. Invest New Drugs 33: 969-976, 2015.

9. Schech A, Kazi A, Yu S, Shah P and Sabnis G: Histone deacetylase inhibitor entinostat inhibits tumor-initiating cells in triple-negative breast cancer cells. Mol Cancer Ther 14: 1848-1857, 2015

10. Chiu HW, Yeh YL, Wang YC, Huang WJ, Chen YA, Chiou YS Ho SY, Lin P and Wang YJ: Suberoylanilide hydroxamic acid, an inhibitor of histone deacetylase, enhances radiosensitivity and suppresses lung metastasis in breast cancer in vitro and in vivo. PloS One 8: e76340, 2013.

11. Min A, Im SA, Kim DK, Song SH, Kim HJ, Lee KH, Kim TY, Han SW, Oh DY, Kim TY, et al: Histone deacetylase inhibitor, suberoylanilide hydroxamic acid (SAHA), enhances anti-tumor effects of the poly (ADP-ribose) polymerase (PARP) inhibitor olaparib in triple-negative breast cancer cells. Breast Cancer Res 17: 33, 2015

12. Shi YK, Li ZH, Han XQ, Yi JH, Wang ZH, Hou JL, Feng CR, Fang QH, Wang HH, Zhang PF, et al: The histone deacetylase inhibitor suberoylanilide hydroxamic acid induces growth inhibition and enhances taxol-induced cell death in breast cancer. Cancer Chemother Pharmacol 66: 1131-1140, 2010.

13. Gong C, Qu S, Lv XB, Liu B, Tan W, Nie Y, Su F, Liu Q, Yao H and Song E: BRMS1L suppresses breast cancer metastasis by inducing epigenetic silence of FZD10. Nat Commun 5: 5406, 2014.

14. Di Martile M, Del Bufalo D and Trisciuoglio D: The multifaceted role of lysine acetylation in cancer: Prognostic biomarker and therapeutic target. Oncotarget 7: 55789-55810, 2016.

15. Hanahan D and Weinberg RA: Hallmarks of cancer: The next generation. Cell 144: 646-674, 2011.

16. Wong RS: Apoptosis in cancer: From pathogenesis to treatment. J Exp Clin Cancer Res 30: 87, 2011

17. Bennett M, Macdonald K, Chan SW, Luzio JP, Simari R and Weissberg P: Cell surface trafficking of Fas: A rapid mechanism of p53-mediated apoptosis. Science 282: 290-293, 1998.

18. Zuckerman V, Wolyniec K, Sionov RV, Haupt S and Haupt Y: Tumour suppression by p53: The importance of apoptosis and cellular senescence. J Pathol 219: 3-15, 2009.

19. Vousden KH: Apoptosis. p53 and PUMA: A deadly duo. Science 309: 1685-1686, 2005.

20. Hikisz P and Kilianska ZM: PUMA, a critical mediator of cell death-one decade on from its discovery. Cell Mol Biol Lett 17: 646-669, 2012
21. Alaee M, Khaghani S, Behroozfar K, Hesari Z, Ghorbanhosseini SS and Nourbakhsh M: Inhibition of nicotinamide phosphoribosyltransferase induces apoptosis in estrogen receptor-positive MCF-7 breast cancer cells. J Breast Cancer 20: 20-26, 2017.

22. Zuco V, Cassinelli G, Cossa G, Gatti L, Favini E, Tortoreto M, Cominetti D, Scanziani E, Castiglioni V, Cincinelli R, et al: Targeting the invasive phenotype of cisplatin-resistant non-small cell lung cancer cells by a novel histone deacetylase inhibitor. Biochem Pharmacol 94: 79-90, 2015.

23. Zhang H, Shang YP, Chen HY and Li J: Histone deacetylases function as novel potential therapeutic targets for cancer. Hepatol Res 47: 149-159, 2016.

24. Lin TY, Fenger J, Murahari S, Bear MD, Kulp SK, Wang D, Chen CS, Kisseberth WC and London CA: AR-42, a novel HDAC inhibitor, exhibits biologic activity against malignant mast cell lines via down-regulation of constitutively activated Kit. Blood 115: 4217-4225, 2010.

25. Zimmerman B, Sargeant A, Landes K, Fernandez SA, Chen CS and Lairmore MD: Efficacy of novel histone deacetylase inhibitor, AR42, in a mouse model of, human T-lymphotropic virus type 1 adult T cell lymphoma. Leuk Res 35: 1491-1497, 2011.

26. Zhang S, Suvannasankha A, Crean CD, White VL, Chen CS and Farag SS: The novel histone deacetylase inhibitor, AR-42, inhibits gp130/Stat3 pathway and induces apoptosis and cell cycle arrest in multiple myeloma cells. Int J Cancer 129: 204-213, 2011.

27. Balch C, Naegeli K, Nam S, Ballard B, Hyslop A, Melki C, Reilly E, Hur MW and Nephew KP: A unique histone deacetylase inhibitor alters microRNA expression and signal transduction in chemoresistant ovarian cancer cells. Cancer Biol Ther 13: 681-693, 2012.

28. Chen YJ, Wang WH, Wu WY, Hsu CC, Wei LR, Wang SF, Hsu YW, Liaw CC and Tsai WC: Novel histone deacetylase inhibitor AR-42 exhibits antitumor activity in pancreatic cancer cells by affecting multiple biochemical pathways. PloS One 12: e0183368, 2017.

29. Lu YS, Chou CH, Tzen KY, Gao M, Cheng AL, Kulp SK and Cheng JC: Radiosensitizing effect of a phenylbutyrate-derived histone deacetylase inhibitor in hepatocellular carcinoma. Int J Radiat Oncol Biol Phys 83: e181-e189, 2012.

30. Li DR, Zhang H, Peek E, Wang S, Du L, Li G and Chin AI: Synergy of histone-deacetylase inhibitor AR-42 with cisplatin in bladder cancer. J Urol 194: 547-555, 2015.

31. Lv XB, Wu W, Tang X, Wu Y, Zhu Y, Liu Y, Cui X, Chu J, $\mathrm{Hu}$ P, Li J, et al: Regulation of SOX10 stability via ubiquitination-mediated degradation by Fbxw $7 \alpha$ modulates melanoma cell migration. Oncotarget 6: 36370-36382, 2015.

32. Livak KJ and Schmittgen TD: Analysis of relative gene expression data using real-time quantitative PCR and the 2(-delta delta $\mathrm{C}(\mathrm{T}))$ method. Methods 25: 402-408, 2001.

33. Wagner T, Brand P, Heinzel T and Krämer $\mathrm{OH}$ : Histone deacetylase 2 controls p53 and is a critical factor in tumorigenesis. Biochim Biophys Acta 1846: 524-538, 2014

34. Tang Y, Zhao W, Chen Y, Zhao Y and Gu W: Acetylation is indispensable for p53 activation. Cell 133: 612-626, 2008.

35. Longley DB, Harkin DP and Johnston PG: 5-fluorouracil: Mechanisms of action and clinical strategies. Nat Rev Cancer 3: 330-338, 2003.

36. De Souza C and Chatterji BP: HDAC inhibitors as novel anti-cancer therapeutics. Recent Pat Anticancer Drug Discov 10: 145-162, 2015.

37. Coates AS, Millar EK, O'Toole SA, Molloy TJ, Viale G, Goldhirsch A, Regan MM, Gelber RD, Sun Z, Castiglione-Gertsch M, et al: Prognostic interaction between expression of p53 and estrogen receptor in patients with node-negative breast cancer: Results from IBCSG Trials VIII and IX. Breast Cancer Res 14: R143, 2012.

38. Wilking MJ, Singh C, Nihal M, Zhong W and Ahmad N: SIRT1 deacetylase is overexpressed in human melanoma and its small molecule inhibition imparts anti-proliferative response via p53 activation. Arch Biochem Biophys 563: 94-100, 2014.

39. Kim JH, Yoon EK, Chung HJ, Park SY, Hong KM, Lee $\mathrm{CH}$, Lee YS, Choi K, Yang Y, Kim K and Kim IH: p53 acetylation enhances Taxol-induced apoptosis in human cancer cells. Apoptosis 18: 110-120, 2013.

40. Ito A, Kawaguchi Y, Lai CH, Kovacs JJ, Higashimoto Y, Appella E and Yao TP: MDM2-HDAC1-mediated deacetylation of p53 is required for its degradation. EMBO J 21: 6236-6245, 2002. 
41. Ouyang L, Shi Z, Zhao S, Wang FT, Zhou TT, Liu B and Bao JK: Programmed cell death pathways in cancer: A review of apoptosis, autophagy and programmed necrosis. Cell Prolif 45: 487-498, 2012.

42. Zheng S, Koh XY, Goh HC, Rahmat SAB, Hwang LA and Lane DP: Inhibiting p53 acetylation reduces cancer chemotoxicity. Cancer Res 77: 4342-4354, 2017.

43. Taieb J, Tabernero J, Mini E, Subtil F, Folprecht G, Van Laethem JL, Thaler J, Bridgewater J, Petersen LN, Blons H, et al: Oxaliplatin, fluorouracil, and leucovorin with or without cetuximab in patients with resected stage III colon cancer (PETACC-8): An open-label, randomised phase 3 trial. Lancet Oncol 15: 862-873, 2014.
44. Han Q, Chen R, Wang F, Chen S, Sun X, Guan X, Yang Y, Peng B, Pan X Li J, et al: Pre-exposure to 50 $\mathrm{Hz}$-electromagnetic fields enhanced the antiproliferative efficacy of 5-fluorouracil in breast cancer MCF-7 cells. PloS One 13: e0192888, 2018.

45. Di Gennaro E, Bruzzese F, Pepe S, Leone A, Delrio P, Subbarayan PR, Avallone A and Budillon A: Modulation of thymidilate synthase and p53 expression by HDAC inhibitor vorinostat resulted in synergistic antitumor effect in combination with $5 \mathrm{FU}$ or raltitrexed. Cancer Biol Ther 8: 782-791, 2009.

46. Bode AM and Dong Z: Post-translational modification of p53 in tumorigenesis. Nat Rev Cancer 4: 793-805, 2004. 